\title{
A Proposal of Present Education for Undergraduation of Engineering Program
}

\author{
Claudio da Rocha Brito, Melany M. Ciampi, Alexandre Botari \\ University Center of Lusiada
}

\begin{abstract}
With the objective of mitigating the devastating effects of the "out of use", it was created many extension, specialization and modernization courses, among others, in its several modalities in the several areas of the human knowledge, being the computing tools in an indispensable strategic position in this process. That preempt need of modernization imposes the need of educational proposals very different from the traditional ones. To supply this lack the "up date information" appeared, with the use of tools and pedagogic and educational methods not essentially orthodox, which implicit objective is the modernization. Not rare the students of under graduation of the scientific-technological areas complain exactly about this distance that makes it imperious among the level of learned information and the level that meet the referring point researches to the subjects or disciplines of its program. Certainly a lot already was done in the sense of decreasing such distance, but the fact is that this is the most important demanded lesson, so much of the priesthood as of the disciples, to know: "to learn how to learn". Giving the student the autonomy necessary to look for the ones that are what, how, when, and where to learn. In this context the education institution cannot and it should supply the fundamental paper of getting into the sense of the under graduation program. This proposal suggests a new " form" to the educational orthodox methods, since it presupposes the use of consecrated methodologies of centuries, such as called seminars, for example, with derivations and innovative aspects when inserting in this the whole available technological tools in the institution, as well as the insert of more flexible and modernized concepts to the usual proposals. It could include a systematic of approach of the scientific technologies and methodologies called "top technology" generally developed in institutes and laboratories a little from distant of the really amount of the under graduating, through this up-to-date version of internal and external seminars to the institution.
\end{abstract}

\section{Introduction}

The scientific-technological revolution that we live propitiated, among many other things, a new sense for the words "out of use". Yes, the word sense "out of use" was always intimately linked to the old, something that lost its usefulness in more appropriate substitutes' face and adapted to the present context. However, the elapsed time so that it happened the out of date is notably inferior to the one of some years ago. 
This same approach has been worth for the information learnt by the student, or the professional, especially the intimately linked to the scientific-technological area, in what s/he says respect to his/her formation. The out of date can be inferior to three years of professional exercise for some modalities, principally in the software area.

The proposal for now presented, demands a commitment from the faculty, once this, in the exercise of educator's priesthood will provide a fomentation atmosphere to the research, motivating the necessary deep as well as valuing the kinetic aspect among the groups that cannot and they should be formed for so much. This methodology presupposes sharply, the total involving of the students once the largest task will be shown extra-class, therefore, depending of a certain academic autonomy. So this exercise will result in countless benefits to the student in a way that will join to their knowledge necessary aspects the professional life when persevering in the incessant search in the scientific and technological borders.

The modern man needs to develop different abilities while s/he absorbs and memorizes information and facts in the several sources of the knowledge. And this proposal tries to position the student in this border, helping her/him to notice the need of this autonomy. This autonomy that, gradually, the student should possess to become an inserted professional in the current context. Maybe a step ahead of her/his time, having in mind that the road for non-present knowledge is dangerously turning shorter and shorter.

Evidently there is not the pretense of approaching in this proposal under graduation program the whole gigantic volume of available information, even in the specific areas, of the researches and called advanced projects. It will allow a healthy acquaintance by the point of view of the modernization, with the "top technology". Principally to insert the academic in this existent extremely dynamic context, once this way the students will get acquainted with the means, the tools and the methodologies of which s/he can make use. If, when, and how much it is necessary to the exercise of future professional life.

\section{Lusiada University Center}

Before describing the proposed methodology, let's tell about the Lusiada University Center, which as many Universities in Brazil is very young one.

In 1967 the Lusiada Foundation was created and it started its activities with the Medical Science College.

In 1969 Management College began and after having consolidated the two Colleges, other Colleges has come. Finally in 1993 the Education Ministry of Brazil recognized the Lusiada as a University Center.

The main characteristic of University Center of Lusiada is the preoccupation with the excellence of education that it offers. This characteristic is expressed in its modern and well-equipped laboratories, libraries and research centers. 
Besides a high level of Faculty with 400 members, the University Center of Lusiada also maintains services to the community. By an agreement between the University and the city Hospital, the "Guilherme Alvaro Hospital" can receive around 11 thousands patients per month. It has 220 places and 22 are reserved for Aids patients. All its Research Centers develop a kind of work to the community, which enriches their work too ${ }^{1}$.

\section{The New Paradigm of Education and Environmental Engineering Programs}

The urgent challenge of education institutions presently is to discuss and find solutions for the equation: What is necessary to form professionals ready to face the competitiveness in according to the new paradigm of complex, mutable and uncertain work environment? Or what to do to change it all?

In a new era, which the supremacy of information and the knowledge are widely preached, the formation of a professional becomes a crucial factor for success.

The new paradigm preaches that the capital is the intellect and people are the most important, but by the other hand it is still difficult the total absorption of this new model of development. Why? Because there is the natural resistance of a person to re-structure her/himself cognitively and emotionally making possible the learning and principally the creation of concepts completely new.

So following these tendencies the engineering education institutions in Brazil are, let's say, running fast to form a new engineer. New programs have been conceived, new approaches, new laboratories and so on. Changes have been happening and many of them are successful. Lusiada's program for engineering education is one of the successful new kind of forming good engineers prepared to face next millenium.

The premise that a global vision, therefore generalist, of the biological cycles and the cycles of the processes of human interference as well as its development. The co relations, interfaces and power demand paradoxically, a deep knowledge of the several areas of human knowledge, mainly the capacity to visualize and to establish the "connection synapses" among these areas (physics, mathematics, biology and chemistry, essentially).

\section{The Engineering Education Project}

The coordinating team of Lusiada Engineering School has conceived and developed a project of an engineering program, under graduation, five years, which main characteristic is the inclusion of new courses and the effective work in projects ${ }^{2}$. So besides the basic science courses, basic engineering courses and specific engineering courses ${ }^{3}$, other two blocs of courses were added and they are:

- the Sciences of Earth, which includes: Meteorology; Geology; Geography (emphasizing Human Geography);

- the Cosmology, which includes: Astrophysics; Physics; Astronomy; Mathematics. 
Another special course was included because of its importance to the comprehension of the whole aspect of human kind, the Sociology, with an emphasis in Social Movements ${ }^{4}$.

The new courses are all distributed along the five years program in a way that they can be moved without any loss to the program ${ }^{5}$.

These courses allied with the basic science courses and the basic engineering courses can provide to the students a new kind of formation, which is much more dynamic and general ${ }^{6}$.

\section{The Curricula}

So the following subjects are part of the curricula that attends a minimum of the resolution 48/76 of April 27 of 1976 from CFE - Federal Council of Education about the curricula directress ${ }^{7}$. And they are:

- Algebra: The Whole Numbers; Relationships and Functions; Cardinality of Groups; Groups; Subgroups; Recurrent groups; Classes Laterals; Groups of Permutation; Theorem of Cayley and Geometric Groups; Normal Subgroups; Homomorfisms; Groups Quotients; Groups Finite Abilene; Theorems of Sylow. Rings; Domains of Integrity; Homomorfisms; Isomorfisms; Ideals; Rings Quotients; Ideal Cousins and Maximal; Characteristic; Domains of Main Ideals; Domains Euclidean; Rings of Polynomials; Theory of the Bodies.

- Calculus: Properties of real numbers; Real functions of a real variable; Some elementary functions; Limit; Continuity; Derived; Theorem of the Medium Value; Applications of the derived; Anti derivative; Integral of Riemann; Fundamental theorem of the Calculus; Applications of the integral; Logarithmic and exponential functions; Integration methods; Integral inappropriate; Applications of the integral of Riemann; Sequences and numeric series; Series of potencies; Vectorial functions; Curves. Real functions of several real variables; Limit; Continuity; Derived partial; Derived directional and gradient; Differentiability; Applications. - Analytical Geometry: Vectors; Lineal dependence; Bases; Product to climb; Vectorial product; Cartesian coordinates; Translation and rotation; Straight line and plans; Distance and angle; Polar, cylindrical and spherical coordinates; Conical; Reduced equations of the quadratic surfaces; Vectors; Plans, straight line and spheres in the and 3; Vectorial spaces and transformations of coordinates; Head offices, decisive, and lineal equations; Transformations ortogonals and rotations in the space of 3 dimensions.

- Equations Differential: Introduction; Equations Differentiate Lineal of 1a. Order and applications; (Equations of Bernoulli and Ricatti); Equations Differentiate Lineal of 2a. Order; Equations Differentiate Lineal of order n; Systems of Equations Differentiate Lineal; Solution of Equations and of Systems of Equations you Differentiate Ordinary using Transformed of Laplace; Solutions of Equations Differentiate Ordinary using series of potencies.

- Numerical Calculus: vectorial fields and flows; Theorem of the inverse function; Theorem of the implicit function; Ends of functions of two variables; Multipliers of Lagrange; Integral multiple; Integral of line; Divergent and rotational; Integral of surface; Theorems of Green, Gauss and Stokes; Real and complex vectorial Applications Spaces; Lineal dependence; Base; Dimension; Subspaces; It adds direct; Lineal transformations; Nucleus and image; Isomorphism; Head office of a lineal transformation; Autoclaves and autovectors; Subspaces invariant; 
Diagonalization of operators; It forms canonical of Jordan; Spaces with internal product; Ortogonality; Isometrics; Solemnity-attached operators.

- Mathematical Modeling: Basic Concept: models versus real problem; Mathematical model; Mathematical Computer; Computation; Simulation; Studies of cases with: Elementary models, middlemen and complex; The use of packages computer, Implementation versus computer packages.

- Probability and Statistical: Theory of the Probability; Random variable; Variables allegory conjunct; Analytic models of discreet allegory phenomenon; Analytic models of continuous random phenomenon; Techniques for sampling; Descriptive statistics; Statistical inference; Distribution standards; Punctual estimate and for trust interval; Test of hypotheses; Regression and correlation.

- Mechanics: Foundations and basic concepts of the classic Mechanics; Systems of units; Systems of forces; Attrition; Balance of systems of forks and rigid bodies; Moment and centeroids; Kinematics of the point, of the straight line and of the rigid body in the plan; Mass center and moment of inertia of rigid bodies; Dynamics of the particle and of the rigid body; Movement equations; Work; Energy; Amount of movement; Pulse.

-Thermodynamics: Static of the fluids; Pressure; Law zero of the Thermodynamics; Properties of the you nourish pure, First Law of the Thermodynamics; Swinging of energy / Second Law of the Thermodynamics.

- Modern Physics: Nature corpuscular of the radiation; Law of Plank; Radiation of the black body; Photoelectric effect; Atom of Rutherford; Atom of Bohr; Spectrum of the hydrogen; Statistics of Maxwell-Boltzman; Distribution of Fermi-Dirac; Distribution of Bose-Einstein. - Electromagnetism: Field and electric potential; Material dielectric; Capacitance; Electric circuits; Magnetic field; magnetic properties of the matter, and induction electromagnectic. - Optical: Nature and propagation of the light; Optical geometric; Polarization, interference and diffraction; Study and application of emission laser.

- Fundamental Chemistry: balance material; estecquiometric; It structures of the matter it Controls periodic and its properties; Structures, forces intermolecular, State of aggregation of the matter, gases, liquids and solids, state changes; Solutions, diluted solutions; Colloidal dispersions, surface phenomenon; Chemical thermodynamics; Chemical balance; Balance in solution; Electrochemistry and piles; Chemical kinetics; Chemistry of the materials; Contamination and residues.

- Biology: To analyze the natural resources, with focus in the ecosystems of Brazil, and the handling methods for a rational use of the same ones; Natural resources of Brazil; Environment and sustained development; Natural resources and development; Methodologies and evaluation techniques; Integral handling of the resources.

- Phenomenon of Transports: Equation of the continuity; Mechanisms of transports; Mechanisms of molecular diffusion; Swinging differential and I balance integral on a property; Constituent equations; Coordinates materials and space; Equation of the movements; Equation of Navier Stokes; Flowing Newtonian and no-Newtonian; Attrition coefficients; Law of Fourier; Equation of the energy; Law of Newton's refreshing; Equation of the continuity for binary systems; Concentration profile for binary systems; Law of Fick.

- Heat Transfer: Transport of energy for conduction, convection and for radiation; Applications of the Law of Fourier; Thermal conductivity; Coefficients of transfer of energy; I calculate of coefficients; Transfer of energy with phase change; Condensation; Simple Conversions; Total 
coefficients of transfer; Incrustation factors; Serpentines; Double Conversions; Simplified methods and complex for conversions; Pressure falls; Condensers; Evaporation; I calculate of evaporators of simple effect and of multiple effect; Radiation; Heaters to direct fire; Ovens.

- Ecology: To check the necessary training for distinction between the several ecosystems of the incorporation of the concepts of matter cycles and energy; Basic ecological concepts of habitation, habitat and atmosphere; Set and niche; Populations, communities and ecosystems; Distribution and abundance; The communities' structures and ecological succession; Indicative species; Biodegradability; Assimilative capacity and auto depuration.

- Transfer of mass and energy: Dimensional consistency; Theory of the dimensional similarity; Techniques for generation of groups dimensionless; Beginning of the mass conservation; I balance total of mass; I balance for component; Continuous processing and for lots; Mass swinging in physical operations; Calculations estecquiometrics; Mass swinging in processes co derivation; General equation of the swinging of energy; General equation of the swinging of energy; Equation of Bernoulli; Swinging of energy in groups of I exchange chemical; Integral heat of solution; Mass swinging and energy in mixtures and evaporators; Enthalpy in the reaction, mass swinging and energy in chemical reactions; Mass swinging and energy in transitory regime for simple systems; Equations of Rachford-Rice; and Holland; Dimensionment of tanks; Intermittent distillation; Equation of Rayleigh.

- General Biochemistry: To know the main ones composed biochemical, as well as the main metabolic roads, so much catabolic as anabolic of the alive organisms and its regulation mechanisms; Carbohydrates; Lipids; Proteins and enzymes; Acid nucleic; Vitamins and hormones; Main metabolic roads; Glicolise; Cycle of Krebs; Breathing chain; Beta oxidation; Genetic transcription; Genetic translation.

- General Microbiology: To understand the fundamental paper of it carries out the microorganisms in the generation and resolution of biotechnical problems; Main methods of the microbiology; Nature of the microbial world; Systems of microbial population; the microorganisms and its use in the biotechnology; Isolation methods and selection of microorganisms.

- Hydraulics: Properties of the liquids; Hydrostatics; Kinematics and dynamics of the liquids; Singularities, holes and floodgates; Scoops; Forced conduits; Transitory phenomenon; Battering ram blow; Flow in free surface: evenly varied, gradually varied and especially varied; I begin of the it drags of sediments; Bombs and turbines; Cycle hydrological; Hydraulics of a basin hydrographic; Precipitation; Dropping; Infiltration; Statistical analysis of having given hydrological; Relationships pluviometrics; Storage basins.

- Economy: Offer and it seeks, profitability; Fixed costs and variable costs; Financial States; Working capital concept; Market concept; Market structures; Evaluation of projects; Approaches for factibility of projects; Approaches for selection of technologies; Determination of balance point; Capital recovery and methods of I calculate of depreciation; Indexes of costs; Team costs; Profitability and usefulness; Rate of investment recovery; Economic swinging. - Applied Right to the Environment: Environmental legislation, municipal environmental Laws; It structures of CETESB; Concepts, beginnings and field of application of the Environmental Right; Objectives, Beginnings and Instruments of the National Politics of the environment; The National system and the environment; Environmental zoning; Right Urbanism; Study of Environmental Impact; Environmental licensing; Penalties; Juridical aspects of the Environmental Pollution; The repair of the Ecological damage. 
- General Mechanics: Static; Preliminary notions; Systems of you force; Polar moment; Axial moment; Cartesian expressions of the moments; Central axis; Moment minimum; Reduction of a system of forks; Moment of transport; Static of the material point; Static of the solid, linked Systems and trellis; Static of the cable; Attrition, virtual Work and Kinematics.

- Topography: Fundamental concepts; Scales; Measurement of angles and distances; Topographical instruments; Planimetry: polygonal and detail; Taqueometry; I draw topographical and representation of the relief; Leveling; Calculation of areas and volumes; Location of projects; Studies on the topographical plant; Projections UTM; GPS geodesic position for satellite; Aerophotogrametry notions and remote sensorial.

- Treatment of Solid Residues: Generation of solid residues; Qualitative and quantitative characterization; Environmental impact; Toxicology and echo-toxicology applied; Biological and physical-chemical foundations of the treatment of the solid residues; Recovery of materials; Recycling; reemployment; re utilization; metalization; thermal treatments: incineration and pyrolysis; sanitary embankments; Industrial embankments; bioconversors.

- Environmental Geology: Geotectonic Engineering paper in the preservation of the environment; Polluters transport in porous means: percolation, advention, dispersion; Effluents disposition and solid residues; Geosynthetic use; Rejections deposits and mining; Barrages built with the own rejections; Sanitary embankments; Risks geotechnics of the use of residues and not very conventional materials; Impact geotechnical of civil works: highways, tunnels barrages, etc; Use of systems of geographical information (SIG) for choice of alternatives with minimization of the impact geotechnical; Analysis of risks and analysis of decisions for choice of alternatives (of plan, of location, of conception) in civil projects; Minimization of risks urban geotechnics. - Administration of the Natural Resources: Atmosphere; Lithosphere; Hydrosphere; Biosphere; Flow of energy; Matter flow; Studies of the new scientific, political and philosophical paradigms; Evolution of the environmental politics in Brazil; Control of environmental quality; Mathematical models.

- Mechanics of the Soils: Introduction to the Mechanics of the Soils; Physical indexes of soils; Granulometry. Limits of Atterberg; Consistency and relative compactness; Classification of the soils; Search of the underground; Tensions in the soil due to the own weight; Permeability of the soils; Percolation tensions; Flow unidimensional; Flow bidimensional; Notions of flow net; Tensions in the underground owed to applied loads; Press down: values of you press down immediate and for adensament; Theory of the adensament; Evolution of you press down with the time; Tension state in the soils; Resistance to the cisalhament of the soils; Plastic balance; Notions on earth thrust; Laboratory activities: the) identification, classification, specific weight, humidity, molding; b) granulometry and limits of Atterberg; c) density of the grains; d) permeability; and) adensament; f) rehearsal of direct cisalhament; g) rehearsals of compression triaxial; Survey of simple recognition.

- Reports of Environmental Impacts: Actors; Scenarios; Objectives; Approaches; classic employees in the classification of environmental impacts: checklist, head office cause x effect, characterization maps; Monocriteria instruments and pluricriteria.

- Management: General theory of the administration; Origin, evolution, theory and techniques of the administration; Contemporary administration; Vision systemic of the administration; Conflicts, changes and development of the administration; Theory, practice and study of cases; Planning and managerial organization; Sections and basic functions of the company; integrated planning; Mission, objectives and strategies of the administration; decision Process; Models and 
technical organizations; He/she practices of the administration of companies; Efficiency and effectiveness in administration; Shared administration and participate.

- Treatment of Liquid Residues: Relationships of swinging of masses in ecosystems; Water Resources; Cycles biogeochemicals; Composed organometalics; Pollution for petroleum and derived; Surfactants, Biocides; Resiliency; Balance models and kinetic models in aquatic systems; Alkalinity and carbonates: composition and balance in natural and polluted systems; Precipitation reactions and breakup and oxy-reduction and the characteristics physicalchemistries of the natural waters and of effluents, Behavior of toxicant organic compositions in the environment; Microbiology of the pollution of the waters; Biodegradation of toxicant compositions; Biological treatment; Growth in suspensions; Biofilms; Treatment anaerobic; Removal of nutritious; Effluents Reutilization; Main treatments of waters residuals; Clotting; Flocculation; Sedimentation; Flotation; aeration; Stripping; Filtration; Disaffection; Oxidation; Adsorption; It changes ionic; Use of membranes.

- Environmental Administration: Planning; Stages and typology of the planning; Planning as process in a market economy; Urban and regional planning in the Brazilian context; Analysis of plans: methodology and evaluation of implementation of plans; Estimate of costs and presupposed of operation; Organization studies, financing and evaluation.

- Treatment of Gaseous Residues: Systems of control of atmospheric pollution; Control of important arthropods for the public health; Control of rodents; Activities of public cleaning; Sound pollution and vibration; Processes and legal mechanisms for control and environmental preservation; Comfort definition; I comfort acoustic: Human answer to the sound, desirable limits, sound pollution, urban noise; Other comfort factors; Physical processes that happen in the atmosphere; Meteorological phenomenon and basic instruments of Measures; Meteorological stations; Evaluation and Control of Processes and Energy Systems Causes of Atmospheric Pollution; Analysis and Instrumentation for Indication and Control of the Coming Atmospheric Pollution of Flows of Energy and Matter; Notions of Right and Referring Environmental Politics to the Atmospheric Pollution

- Technical Drawing: Use and I handle of the instrumental graph; Standardization of the paper formats; Scales and its applications; Conventions of the graphic lines; quotation of the drawings; Letters and ciphers; Fundamental geometric constructions; Use of the projections Mongeanas; Graphic representation of the orthographic views; Orthographic views of an association of geometric solids; System DIN; Auxiliary views; Views sectionals; Intersections of solids and developments; Graphic construction of the ellipse; Projections axonometrics; Projections axonometrics of you sin prismatic and cylindrical; General notions of the projection systems; Method projection mongean; Polyhedrons representation; Conical sections.

- Work Term: During a period of four months at the end or in the beginning of the last two years, the students work effectively in an enterprise. A professor, who altogether the supervisor of the company gives the student the work in part of a project, supervises them. They have to accomplish their work so that another student that will replace him in the project performs the next step. This experience has been very grateful once the students and the companies are satisfied with this scheme of work. The teachers/advisors, they are happy once they have a feedback for their next term.

\section{The criterion of Evaluation}


The evaluation criterion is up to the Professor responsible for each course ${ }^{8}$. It can be done by means of works, seminars and tests or any other method. This flexibility ${ }^{9}$ is important because of the objective of the courses, which is to give the student an opportunity to develop their abilities of create solutions in according to the demands of environment, helping to decrease the impact of progress over nature and men. For sure a minimum score is required to the approval for next year ${ }^{10}$.

Besides good faculty members, the students can count with well-equipped Libraries, Internet access and a staff of technicians specially trained for helping.

\section{Conclusions}

In a country like Brazil is very important to form professionals committed with the environment in any area, principally environmental engineers. Why? Because Brazil despite of all problems of management it has, it is still a Country, which nature is in many places intact. So it is possible to preserve the largest part of national lands and to promote the development and the progress of the Country.

This professional of environmental engineering has to be very well qualified, with skills to help the promotion of sustainable development. S/he has to be a professional with scientific mind, capable of finding solutions in according to the local context inserted in a global context. It is the ability of creating technology to be used to the welfare of contemporary society, viewing the future year ${ }^{11}$.

The effective work in projects exposes the students to the real environmental problems and this provides the interface of the theory and the practice. This seeking for the right solution for such problems enlarges their academic horizons considerably.

Such kind of education prepares the students for the effective professional practice in a more solid way, coherent with the complex demand of present world.

\section{Bibliography}

1. Lusiada, F: "Centro de Estudos Superiores da Fundação Lusiada", Santos: UNILUS. 1994.

2. Brito, C. da R. "La Formación del Profesional de Ingeniería y los desafíos de la Nueva Realidad Mundial", In: Reunión Nacional de Facultades de Ingeniería, 19., Cartagena de Indias, 1999. 1999 Ingeniería, Calidad y Desarrollo. Cartagena de Indias: ACOFI, 1999. p. 341-346.

3. Brito, C. da R.; Ciampi, M. M. "The Impact of Globalization in Project of Curriculum of an Engineering Program". In: Internationalen Symposiums "Ingenieurpädagogik'2000”, 29., Biel, 2000. Unique and Excellent: Ingenieurausbildung im 21. Jahrhundert. Biel-Bienne: IGIP, 2000. p. 533-6.

4. Brito, C. da R.; Ciampi, M. M. "New Skills / Concepts for New Engineers. In: Interamerican Conference on Engineering and Technology Education, 6., Cincinnati, 2000. Proceedings INTERTECH-2000. Cincinnati:

INTERTECH, 2000. (in CD-ROM). 
5. Brito, C. da R.; Ciampi, M. M. "Searching for a new Engineer. In: American Society of Engineering Education Annual Conference, 107., St. Louis, 2000. 2000 ASEE Annual Conference Proceedings. St. Louis: ASEE, 2000. (in CD-ROM).

6. Brito, C. da R.; Ciampi, M. M. "La Formación Humanística del Ingeniero en Brasil. In: Conference Nacional de Ingeniería, 27., Toluca, 2000. La Formación Humanistica del Ingeniero. Toluca: ANFEI, 2000. (in CD-ROM). 7. Brito, C. da R.; Ciampi, M. M. "Development of a New Engineering Education Scheme in Brazil. In: International Conference on Engineering Education, 6., Taipei, 2000. Proceedings ICEE-2000. Taipei: ICEE, 2000. (in CD-ROM).

8. Brito, C. da R.; Ciampi, M. M.; Botari, A. "Environmental Engineering Education In Third Millenium. In: International Conference on Engineering and Computer Education, 2., São Paulo, 2000. Proceedings ICECE-2000. São Paulo: ICECE, 2000. (in CD-ROM).

9. Brito, C. da R.; Ciampi, M. M.; Botari, A. "Uma Proposta de Ensino Contextualizado para a Graduação. In: Congreso Argentino de Enseñanza de Ingenieria, 3., Bahía Blanca, 2000. Anales del 3er Congreso Argentino de Enseñanza de Ingeniería. Bahía Blanca: CONFEDI, 2000. v. 1, p. 121-125.

10. Brito, C. da R.; Ciampi, M. M. "Humanistic and Modern Education for Engineering in the new Society. In: Frontiers in Education Annual Conference, 30., Kansas City, 2000. 2000 FIE Annual Conference Proceedings. Kansas City: FIE, 2000. v. 1, p. T2F 11-14.

11. Longo, W. P. e; Telles, M. H. C. "Programa de desenvolvimento das Engenharias: Situação Atual". Revista de Ensino de Engenharia, 18. Rio de Janeiro: ABENGE,1998 p.74-82.

\section{CLAUDIO DA ROCHA BRITO}

Claudio da Rocha Brito is a Professor of Electrical and Computer Engineering and Head of Department of University Center of Lusiada. He is Vice-President of Brazilian Chapter of Education Society of the Institute of Electrical and Electronics Engineers, Inc - IEEE - ES, Member of the Executive Committee of Ibero-American Association of Engineering Education Institutions - ASIBEI, Director of Brazilian Network of Engineering RBE/SP, Secretary of Santos region of SBPC - Brazilian Association for the Advancement of Science, Councilor of Urban Development City Council CMDU, Director of Brazilian Environmental Research Center - NPAB. He is also Presidency Adviser for International Relations in the ABENGE - Brazilian Society for Engineering Education. Dr. Claudio da Rocha Brito has received a B.S. degree in Electrical Engineering, B.S. degree in Mathematics, B.S. degree in Physics, M.S. and Ph.D. in Electrical Engineering all from the University of São Paulo. He was the General Secretary of ICECE'99, the Technical Program Chairman of ICECE'2000 and he is the General Chairman of INTERTECH 2002.

\section{MELANY MARIA CIAMPI}

Melany Maria Ciampi Tenente da Rocha Brito is a Researcher of University Center of Lusiada. She is Secretary of Brazilian Chapter of Education Society of the Institute of Electrical and Electronics Engineers, Inc - IEEE - ES She belongs to the State Council of SBPC - Brazilian Association for the Advancement of Science and she is Councilor of Brazilian Environmental Research Center - NPAB. She has received a B.S. degree from Catholic University of Santos. She has many works in Engineering Education in several International Congresses. She was the Exhibits Chair of ICECE`99, the Publications Chair of ICECE'2000 and she is the Technical Chair of INTERTECH 2002.

\section{ALEXANDRE BOTARI}

Alexandre Botari is a Researcher of University Center of Lusiada. He has received a B.S. degree in Civil Engineering from Catholic University of Santos. 